\title{
PREVALENCE AND ASSOCIATED FACTORS OF SUICIDE AMONG PREGNANT WOMEN AT ZAGAZIG UNIVERSITY HOSPITALS
}

\author{
Mohamed Abdelghani Moustafa , Usama Mahmoud Youssef , Nagy Fawzy Sleem ,Reham \\ Hassan Mohamed El- Hanafy \\ Psychiatry Departments, Faculty of Medicine, Zagazig University, Egypt
}

\section{Corresponding author}

Reham Hassan Mohamed ElHanafy

amidreaming18@gmail.com
ABSTRACT

Background: Pregnant women are at increased risk for suicidal ideation and behaviors (SIB) compared to the general population. To our knowledge, this is the first study in Egypt discussing the prevalence and risk factors of suicide among pregnant women. The study aimed to estimate the frequency of suicide and suicidal ideation and identify the socio-demographic and clinical determinants of suicide and suicidal ideation among pregnant women at Zagagzig University Hospitals.

Methods: A sample of 167 pregnant women received prenatal care at Obstetrics and Gynecology Outpatient clinic, Zagazig University hospitals. A simple questionnaire was structured for all participants to collect data on socio-demographic data, clinical and obstetric history \& exposure interpersonal violence. The psychometric assessment was done which included: Beck Suicidal Ideation Scale (BSS), Zagazig Depression Scale (ZDS), and Hamilton Anxiety Rating Scale (HAM-A).

Results: The prevalence of current suicidal risk (CSR) among pregnant women was $22.2 \%$, this value could be subdivided into suicidal ideation of $20.4 \%$ and suicidal attempt of $1.8 \%$.Women who had anxiety/ depression or had exposed to current partner aggressiveness were significantly more likely to have had current suicide risk (CSR).

Conclusion: Pregnant women at the greatest risk for current suicide risk (CSR) were those who were depressed/anxious or had experienced some form of current partner aggressiveness. With the high prevalence of these conditions, attention should be given to the establishment of adequate mental health treatment programs for pregnant women.

Keywords: Pregnancy, current suicide risk (CSR), anxiety/ depression, current partner aggressiveness.

\section{INTRODUCTION}

Suici uicide is defined as the act of intentionally ending one's own life. Suicide is more specifically classified into three categories: suicidal ideation, suicide plan and suicide attempt ${ }^{[1]}$. Over 16,000,000 people worldwide attempt suicide every year, and about 800,000 people die by suicide. In 2012, suicide accounted for $1.4 \%$ of all deaths worldwide, making it the $15^{\text {th }}$ leading cause of death ${ }^{[2]}$.

The move from pregnancy to motherhood is an interesting life experience and can adversely influence women's mental well-being ${ }^{[3]}$. Depression and anxiety are common during and after pregnancy and may increase the risks of prolonged labor, low birth weight (LBW) and offspring malnutrition ${ }^{[3,4,5]}$
Suicidal behaviors occur in $3 \%$ to $14 \%$ of the obstetric population [6,7] Depressed, and anxious pregnant women have higher suicide risk compared to ones without these disorders ${ }^{[8]}$. The following factors have been listed as increasing the risk of suicidal behavior during pregnancy: younger age, unemployment, unplanned pregnancy, induced abortion, violence between intimate partners, low level of social support, drug abuse and psychiatric disorders such as depression and anxiety ${ }^{[7,8,9,10,11,12,13,14]}$.

No accurate data is available about the problem of suicide in pregnant women at Zagagzig University Hospitals, so we need to figure out this issue and its associates. Thus, this study aimed to describe the prevalence of suicide during pregnancy and to identify the 
factors associated with the current suicide SUBJECTS \& METHODS

A randomized cross-sectional study was done for 167 pregnant women, received prenatal care at Obstetrics and Gynecology Outpatient clinic, Zagazig University hospitals. Sample was calculated to be 167 pregnant women, using open Epi VII program, at confidence interval $95 \%$ and power of test $80 \%$, as the total number of pregnant females attending to the clinic was 360. Recruitment was conducted between 1 October 2017 and 30 June 2018 and women who met the following eligibility criteria at enrollment were invited to participate: 1) Married pregnant women. 2) Age of pregnant women ranged from 20 to 40 years. We excluded

women who abandoned prenatal care, had any physical, mental retardation, substance abuse, and known cases with psychiatric disorders, widowed or divorced pregnant women \& high-risk pregnancy. After exclusions, the final sample comprised of 167 pregnant women. Ethical committee approval and written informed consent were obtained. A questionnaire about their socioeconomic status, clinical, obstetric history \& interpersonal violence was administered.

The Psychometric assessments that were done by a psychiatrist were:

A) Beck Scale for Suicide Ideation (BSS) ${ }^{[15]}$ Clinically, BSS has been described as the "clinical scale of choice" for the assessment of suicidality ${ }^{[16]}$. It is a 21 -item measure of which only the first 19 items are scored. All items consist of three response options, ranging from 0 to 2 . Total scores, which ranged from 0 to 38 , ware obtained by adding the item values. Although there exist no published recommendations for BSS cutoff scores, [16], Cochrane-Brink used a cutoff of 24, which produced excellent predictive values ${ }^{[17]}$

B) Zagazig depression scale (ZDS)
[18] this was a self-rating instrument for
measuring the severity of depression.
Presented in the form of 52 questions written
in Arabic, the answer for each question is
either "Yes" or "No" and the questions
covered 17 items involving the symptoms and
signs of depression. With a total score ranged
of[ $0>30],(0-9)$ no depression, $(10-19)$

March 2019 Volume 25 Issue 2 risk.

mild depression,(20 - 29) moderate depression,(30 - more) severe depression.

C) Hamilton anxiety scale (HAM-A) ${ }^{[19]}$ is a widely used and well-validated tool for measuring the severity of a patient's anxiety. It consisted of 14 symptom-defined elements and catered for both psychological and somatic symptoms The HAM-A took 15-20 minutes to complete the interview and score the results. Each item is scored on a 5-point scale, ranging from 0 (not present) to 4 (severe), with a total score range of $0-56$, where 0-13 normal range, 14-17 indicates mild severity, $18-24$ moderate severity and 25 and over severe anxiety.

D) Socio-demographic and clinical data of pregnant women were collected via a semistructured questionnaire specifically developed for this study. This data included age, occupation, residence, educational level, income, husband occupation and smoking habit of the husband, obstetric history (number of previous abortions, planned or unplanned pregnancy, abortion intention in current pregnancy, number of pregnancies, number of female and male offsprings, abortion attempt in current pregnancy and type of previous labour), history of exposure to abuse, ongoing abuse, past history of suicide ideation and/or attempt and family history of suicide ideation and/or attempt.

N.B: when illiterate women were met, we read the self-rating scales for them, and their responses were recorded.

Data analysis was performed using the software SPSS (Statistical Package for the Social Sciences) version 20. Quantitative variables were described using their means and standard deviations. Categorical variables were described using their absolute frequencies and to compare the proportion of categorical data, chi-square test, and Fisher exact test was used when appropriate. Kolmogorov-Smirnov (distribution-type) and Levene (homogeneity of variances) tests were used to verify assumptions for use in parametric tests. To compare the means of two groups, the independent sample t-test was used when appropriate. A nonparametric test (Mann-Whitney) was used to compare the means when data were not normally 


\section{Mohamed et al...}

distributed and to compare the medians in categorical data. To assess correlations between two continuous variables, Pearson (for normally distributed data) and Spearman (for not normally distributed data) correlation coefficients were used. Binary logistic regression was used to assess the odds ratio of possible variables. The level of statistical significance $(\mathrm{S})$ was set at $5 \% \quad(\mathrm{P}<0.05)$, highly significant difference was present if $\mathrm{p} \leq 0.001$ (HS) and $\mathrm{p}$-value $\geq 0.05$ was considered statistically insignificant (NS).

\section{RESULTS}

The sample consisted of 167 pregnant women with a mean age of 28.7 (S.D. =6.04) years. Most women were educated $(\mathrm{N}=147,88 \%)$, Rural residents $(\mathrm{N}=$ $122,73.1 \%)$, had low income $(\mathrm{N}=83,49.7 \%)$, were housewives $(\mathrm{N}=129,77.2 \%)$, had vaginal delivery (VD) in the previous pregnancy $(\mathrm{N}=54,51.9 \%)$, had unplanned pregnancy $(\mathrm{N}=74,44.3 \%) \&$ present history of abortion intentions $(\mathrm{N}=55,32.9 \%)$ or attempt $(\mathrm{N}=18,10.8 \%)$. Mean of the number of pregnancies was 2.44 (S.D. $=1.51)$, mean of the number of previous abortions was 1.75 (S.D. $=1.08)$, mean of the number of female offsprings was 1.29 (S.D. $=0.57$ ), while mean of the number of male offsprings was 1.17 (S.D. $=0.37) \&$ most of their husbands were skilled workers $(\mathrm{N}=85,50.9 \%)$ [Table 1] . History of suicide ideation only present in 73 (44\%) of the pregnant women while 15 (9\%) had a history of suicide attempt [Figure 1]. Only $4(2 \%)$ pregnant women had a family history of suicide attempt [Figure 2]. ( $\mathrm{N}=152$, $91 \%)$ of the women had depression while $(\mathrm{N}=$ $33,19.8 \%)$ had anxiety [Table 2]. ( $\mathrm{N}=76$,

\section{Zagazig University Medical Journals}

$45.5 \%)$ Of participants had a history of partner aggressiveness, while $(\mathrm{N}=58,34.7 \%)$ of the participants were currently exposed to partner aggressiveness. Furthermore, $(\mathrm{N}=86$, $51.5 \%$ ) of the studied population had a history of exposure to aggressiveness by other persons (father/brother) [Table 3].

The prevalence of current suicidal risk (CSR) among pregnant women was $22.2 \%(\mathrm{~N}=37)$, this value could be subdivided into suicidal ideation of $20.4 \% \quad(\mathrm{~N}=34)$ and suicidal attempt of $1.8 \%(\mathrm{~N}=3)$ [Figure 3]

There was no statistically significant difference between socio-demographic, obstetric data, history, family history of suicide and current suicide risk.

Also, there was no statistically significant difference between the history of aggressiveness by the partner or other persons and the current suicide risk.

But there were statistically significant differences between depression, anxiety, current partner aggressiveness ( $p$ value $=0.007,0.003,0.016$ respectively) and suicide risk in current pregnancy [Table $4 \&$ 5].

Multivariate analysis shows the presence of severe depression significantly increases the likelihood of suicidal risk by about four times while the presence of anxiety substantially increases the likelihood of suicide risk by about three times. Presence of current violence significantly doubled the likelihood of suicidal risk [Table 6].

There was a significant positive correlation between the depression scale and both the anxiety scale and Beck's suicide scale [Table 7]. 

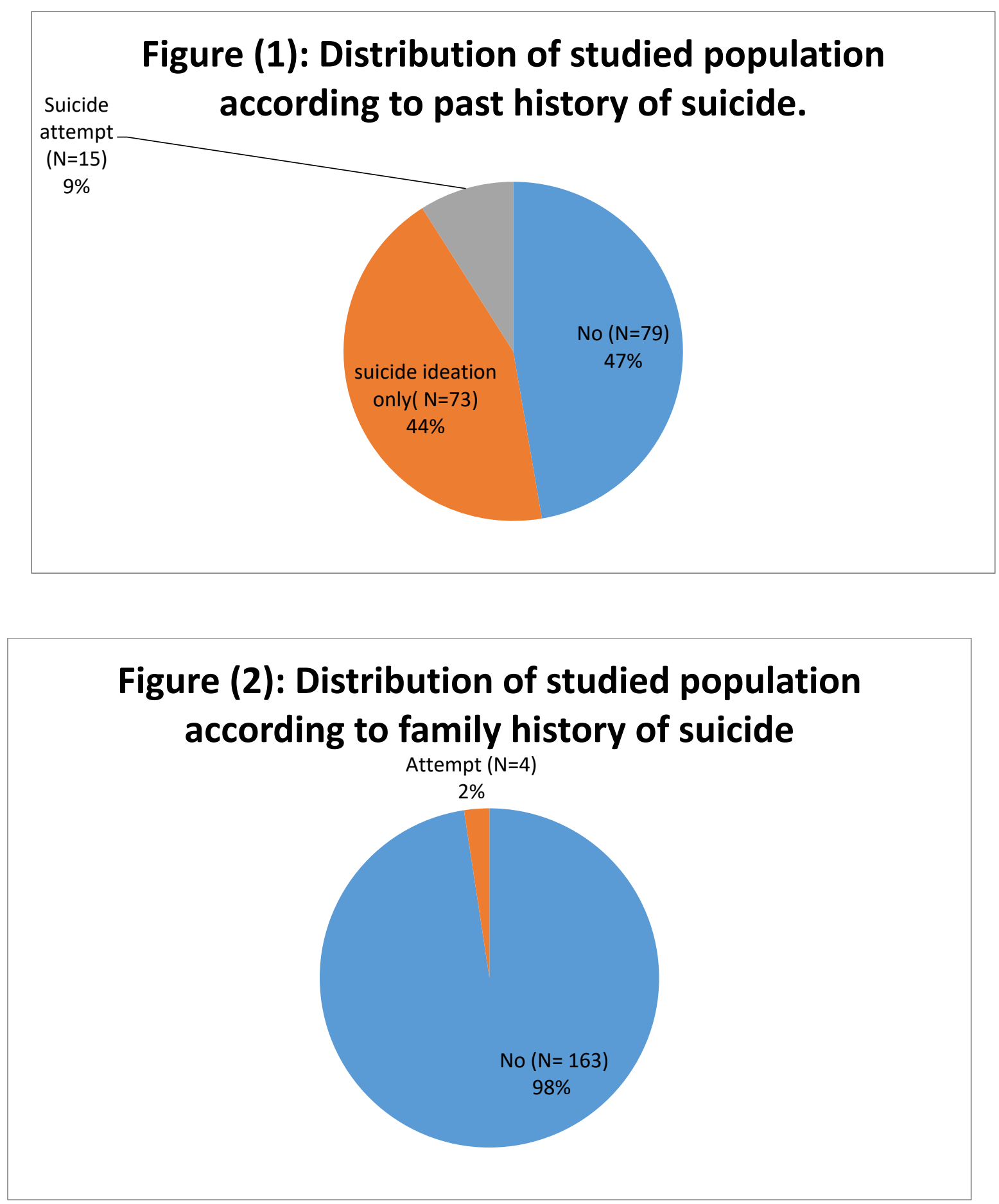


\section{Figure (3) Distribution of studied population according to current suicid risk}

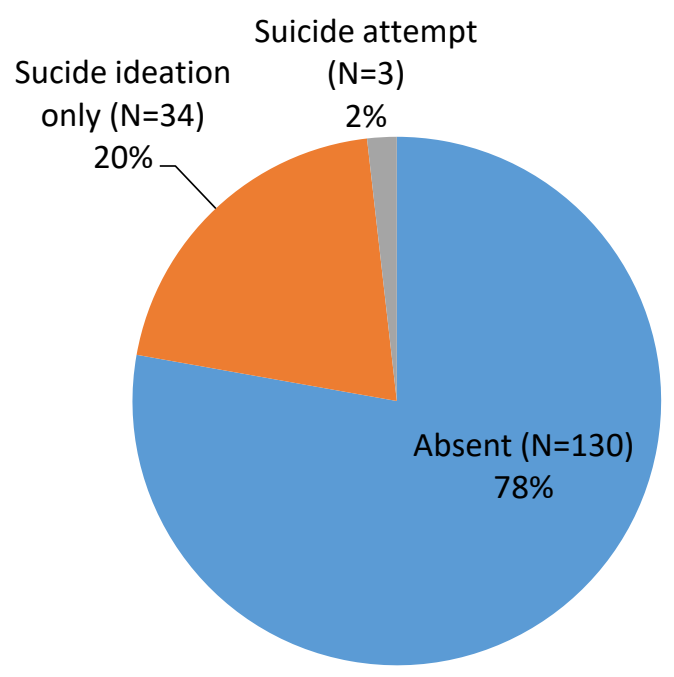

Table 1 Socio-demographic characteristics \& obstetric history of studied population:

\begin{tabular}{|c|c|}
\hline & $\mathbf{N}(\%)$ \\
\hline $\begin{array}{l}\text { Residence: } \\
\text { Rural } \\
\text { Urban }\end{array}$ & $\begin{array}{c}122(73.1) \\
45(26.9) \\
\end{array}$ \\
\hline $\begin{array}{l}\text { Income: } \\
\text { Low } \\
\text { Moderate } \\
\text { High }\end{array}$ & $\begin{array}{l}83(49.7) \\
67(40.1) \\
17(10.2)\end{array}$ \\
\hline $\begin{array}{l}\text { Education: } \\
\text { Illiterate } \\
\text { Educated }\end{array}$ & $\begin{array}{c}20(12) \\
147(88)\end{array}$ \\
\hline $\begin{array}{l}\text { Occupation: } \\
\text { Housewife } \\
\text { Working }\end{array}$ & $\begin{array}{l}129(77.2) \\
38(22.8)\end{array}$ \\
\hline $\begin{array}{l}\text { Husband occupation: } \\
\text { Unskilled } \\
\text { Skilled }\end{array}$ & $\begin{array}{l}82(49.1) \\
85(50.9)\end{array}$ \\
\hline $\begin{array}{l}\text { Type of previous labor: } \\
\text { Vaginal delivery (VD) } \\
\text { Cesarean section (CS) }\end{array}$ & $\begin{array}{l}54(51.9) \\
50(48.1) \\
\end{array}$ \\
\hline $\begin{array}{l}\text { Plan for current pregnancy: } \\
\text { Unplanned } \\
\text { Planned }\end{array}$ & $\begin{array}{r}74(44.3) \\
93(55.7) \\
\end{array}$ \\
\hline $\begin{array}{l}\text { Present history of abortion intentions: } \\
\text { Absent } \\
\text { Present }\end{array}$ & $\begin{array}{c}112(67.1) \\
55(32.9)\end{array}$ \\
\hline $\begin{array}{l}\text { Present history of abortion attempts: } \\
\text { Absent } \\
\text { Present }\end{array}$ & $\begin{array}{c}149(89.2) \\
18(10.8)\end{array}$ \\
\hline & Mean \pm SD \\
\hline
\end{tabular}




\begin{tabular}{|l|c|c|c|}
\hline Age: & $28.7 \pm 6.04$ & \multicolumn{2}{|l|}{$20-45$} \\
\hline & Mean \pm SD & Median & Range \\
\hline Number of pregnancies: & $2.44 \pm 1.51$ & 2 & $1-11$ \\
\hline Number of female offsprings: & $1.29 \pm 0.57$ & 1 & $1-4$ \\
\hline Number of male offsprings: & $1.17 \pm 0.37$ & 1 & $1-2$ \\
\hline Number of previous abortions: & $1.75 \pm 1.08$ & 1 & $1-8$ \\
\hline
\end{tabular}

Table 2 Associated psychiatric history of studied population:

\begin{tabular}{|c|c|c|}
\hline & \multicolumn{2}{|l|}{$\mathbf{N}(\%)$} \\
\hline \multicolumn{3}{|l|}{ Depression } \\
\hline$-\quad$ No & \multicolumn{2}{|l|}{$15(9)$} \\
\hline Mild & \multicolumn{2}{|l|}{$51(30.5)$} \\
\hline Moderate & \multicolumn{2}{|l|}{$77(46.1)$} \\
\hline$-\quad$ Severe & \multicolumn{2}{|l|}{$24(14.4)$} \\
\hline \multicolumn{3}{|l|}{ Beck's suicide scale } \\
\hline$-\quad<24$ & \multicolumn{2}{|c|}{$130(77.8)$} \\
\hline$-\quad \geq 24$ & \multicolumn{2}{|c|}{$37 \quad(22.2)$} \\
\hline \multicolumn{3}{|l|}{ Anxiety: } \\
\hline - Absent & \multicolumn{2}{|c|}{$134(80.2)$} \\
\hline Present & \multicolumn{2}{|c|}{$33(19.8)$} \\
\hline & Mean \pm SD & Range \\
\hline $\begin{array}{llll}\text { - } & \text { Zagazig university depression } \\
\text { scale: } & & & \end{array}$ & $22.04 \pm 8.85$ & $3-42$ \\
\hline$-\quad$ Beck's suicide scale & $9.38 \pm 10.04$ & $0-26$ \\
\hline Hamilton anxiety scale: & $8.85 \pm 5.64$ & $1-24$ \\
\hline
\end{tabular}

Table 3 Exposure to violence among studied population:

\begin{tabular}{|l|c|}
\hline & $\mathbf{N}(\%)$ \\
\hline Past history of partner aggressiveness & \\
\hline$-\quad$ No & $91(54.5)$ \\
$-\quad$ Yes & $76(45.5)$ \\
\hline Past history of other person aggressiveness \\
(father/brother) \\
\hline$-\quad$ No & $81(48.5)$ \\
$-\quad$ Yes & $86(51.5)$ \\
\hline Current partner aggressiveness & $109(65.3)$ \\
\hline$-\quad$ No & $58(34.7)$ \\
\hline
\end{tabular}


Table 4 the relation between associated psychiatric history and suicidal risk in studied population:

\begin{tabular}{|l|l|l|l|l|}
\hline \multirow{2}{*}{} & \multicolumn{2}{|c|}{ Current suicide risk } & \multirow{2}{*}{$\mathbf{X}^{\mathbf{2}}$} & \multirow{2}{*}{ P } \\
\cline { 2 - 3 } & No & Yes & & \\
\cline { 2 - 3 } Depression & $\mathbf{N}(\%)$ & & & \\
No & & $2(5.4)$ & & \\
mild & $13(10)$ & $9(24.3)$ & 9.399 & 0.024 \\
Moderate & $42(32.3)$ & $15(40.5)$ & & $($ S) \\
Severe & $62(47.7)$ & $11(30.6)$ & & \\
\hline Anxiety: & $13(10)$ & $24(64.9)$ & 7.086 & 0.008 \\
Absent & $110(84.6)$ & $13(35.1)$ & & (S) \\
Present & $20(15.4)$ & & \\
\hline
\end{tabular}

(S): Significant p-value $<0.05$

(NS): P-value $>0.05$ is not significant

Table 5 Relation between exposure to violence and suicidal risk in studied population:

\begin{tabular}{|l|l|l|l|l|}
\hline \multirow{2}{*}{} & \multicolumn{2}{|l|}{ Current suicide risk } & \multirow{2}{*}{$\mathbf{X}^{2}$} & \multirow{2}{*}{ P } \\
\cline { 2 - 3 } & No & Yes & & \\
\cline { 2 - 3 } $\begin{array}{l}\text { Past history of partner } \\
\text { aggressiveness: }\end{array}$ & & & \\
No & $72(55.4)$ & $19(51.4)$ & 0.189 & 0.664 \\
Yes & $58(44.6)$ & $18(48.6)$ & & \\
\hline $\begin{array}{l}\text { Past history of other person } \\
\text { aggressiveness: }\end{array}$ & & & & \\
$\begin{array}{l}\text { No } \\
\text { Yes }\end{array}$ & $66(50.8)$ & $15(40.5)$ & 1.206 & 0.272 \\
\hline $\begin{array}{l}\text { Current partner aggressiveness } \\
\text { yes }\end{array}$ & $64(49.2)$ & $22(59.5)$ & & $(\mathrm{NS})$ \\
no & & & & \\
& $39(30)$ & $19(51.4)$ & 5.792 & 0.016 \\
\hline
\end{tabular}

(S): Significant p-value $<0.05$

(NS): P-value $>0.05$ is not significant

Table 6 Multivariate analysis of risk factors for suicide in studied population:

\begin{tabular}{|ll|c|c|c|c|}
\hline & B & OR & C.I. & P \\
\hline- & Severe depression & 1.308 & 3.699 & $1.422-9.623$ & $0.007 *$ \\
\hline- & Anxiety & 0.970 & 2.639 & $1.098-6.345$ & $0.03 *$ \\
\hline- & Current violence (yes) & 0.767 & 2.152 & $1.01-4.727$ & $0.049 *$ \\
\hline
\end{tabular}

Table (7): correlation between depression, Beck's suicide and anxiety scale:

\begin{tabular}{|l|c|c|c|c|c|c|}
\hline & \multicolumn{2}{|c|}{ Depression } & \multicolumn{2}{c|}{ Anxiety } & \multicolumn{2}{c|}{ Suicide } \\
\hline & $\mathrm{r}$ & $\mathrm{P}$ & $\mathrm{r}$ & $\mathrm{P}$ & $\mathrm{r}$ & $\mathrm{P}$ \\
\hline Zag. Depression scale & 1 & & 0.337 & $<0.001$ & 0.393 & $<0.001^{* *}$ \\
\hline Hamilton anxiety scale & 0.337 & $<0.001$ & 1 & & 0.120 & 0.123 \\
\hline Beck's suicide & 0.393 & $<0.001$ & 0.120 & 0.123 & 1 & \\
\hline
\end{tabular}

\section{DISCUSSION}

Suicidal behaviors (e.g., suicidal ideation, suicide plans, and suicide attempts) are the leading causes of injury and death worldwide and are important determinants of maternal

March 2019 Volume 25 Issue 2 mortality in some countries ${ }^{[20]}$. According to a report by the World Health Organization (WHO) over 800,000 individuals die by suicide each year, resulting in an annual global age-standardized suicide rate of 11.4 


\section{Mohamed et al...}

per 100,000 persons ${ }^{[2]}$. Furthermore, for each suicide committed there exist many more suicide attempts that may result in severe injury [21]. Pregnancy creates substantial hormonal and physiological changes, is often followed by stressful social and transitions and is a vulnerable time for the onset of mental disorders ${ }^{[22]}$. There is a growing concern over the increase in suicidal ideation and behavior (SIB) among pregnant women [23]. The study was conducted in Obstetrics and Gynecology Outpatient clinic, Zagazig University Hospitals, Sharkia, Egypt .The sample included 167 pregnant women attending Obstetrics and Gynecology Outpatient clinic for antenatal care, From 1 October 2017 to 30 June 2018.

In our study, we found that the overall prevalence of current suicide risk among pregnant women was $22.2 \%(\mathrm{~N}=37)$, this value could be subdivided into suicidal ideation of $20.4 \% \quad(\mathrm{~N}=34)$ and suicidal attempt of $1.8 \%(\mathrm{~N}=3)$.

These findings are consistent with many studies; research found that $18.4 \%$ of pregnant women had current suicide risk ${ }^{[24]}$. Also, suicide risk was accounted as $19.6 \%$ in a study among low-income Brazilian women in early pregnancy ${ }^{[25]}$; another research found that $23.53 \%$ of pregnant women had current suicide risk [26]. Other researches on suicidality in pregnancy were focused unique on suicide ideation and reported prevalence ranged from $2.7 \%$ and $35 \%$ [11, 12, 14, 27, 28].

Our results are inconsistent with a study which found that $8.1 \%$ of pregnant women demonstrated suicidal potential. This controversy with our results can be explained that this study was done for Brazilian pregnant women (different culture) \& the suicidality was evaluated using only item 10 of the Edinburgh Postnatal Depression Scale (different methodology). Our study was done for Egyptian pregnant women and used a more specific scale for suicidal ideation (Beck suicide ideation scale) ${ }^{[29]}$.

Our results are inconsistent with another study which found that $7.6 \%$ of pregnant women had suicidal ideation in the current pregnancy and $2 \%$ had even made a suicide attempt during the current pregnancy. This controversy with our results can be explained

\section{Zagazig University Medical Journals}

that this study was done for only urban Indian pregnant women who were between 5 and 20 weeks of pregnancy (early in pregnancy), but our study was done for Egyptian pregnant women of both urban and rural residence and at any time during the pregnancy period ${ }^{[30]}$.

Regarding the relationship between suicide and exposure to violence among pregnant women, our study revealed that current suicide risk was more among women who exposed to current partner aggressiveness $(\mathrm{N}=19,51.4 \%)$ and the relation between suicidal risk and exposure to current partner aggressiveness was statistically significant.

The fact that many women chose to remain quiet and few talked to others when subjected to abuse suggests that there may be challenges in seeking help among those who are already marginalized. In Egyptian culture, a woman may resist sharing social adversity to protect her husband and his family. Another barrier to sharing may be the lack of structured social support services available for abused or suicidal women. Abused, shamed, and powerless wives take their own lives to shift the burden of humiliation from themselves to their tormentors. Other researches confirm these findings ${ }^{[8,11,31,32,33]}$.

As has been noted previously, the insecure relationships and intimate partner violence may create an environment which contributes to the development of suicide ideation and behavior in pregnant women ${ }^{[33]}$. In a population-based study of pregnant women in Brazil, there was an increase in the risk for suicidality among women who reported physical abuse within the last 12 months, as compared with their non-abused counterparts [31]. Another study among Pakistani pregnant women revealed a strong relation between both verbal and physical/sexual abuse and both suicidal thoughts and actual attempts ${ }^{[8]}$. Also, another research revealed a strong association between intimate partner violence and suicidal ideation among pregnant women in the U.S, as intimate partner violence during pregnancy was associated with increased risk of suicidal ideation ${ }^{[32]}$.

Research disapproves with our findings, did not find past-year intimate partner violence (IPV) or current IPV to be 


\section{Mohamed et al...}

significantly associated with suicidal ideation during pregnancy in multivariate modeling. This inconsistency could be attributed to; in this study, they used a sample of 2159 pregnant women only $69(3.2 \%)$ of them exposed to current IPV, also this study carried out in the United States in which they made strict laws and punishment for the abuser. While in our study we used a sample of 167 Egyptian pregnant women; 58 (34.7\%) of them exposed to current IPV ${ }^{[12]}$.

Regarding depression, our study found that current suicide risk was highest among women with severe depression $(\mathrm{N}=11$, $30.6 \%$ ) and the relation between depression and current suicide risk was statistically significant. We found that the presences of severe depression significantly increase the likelihood of suicidal risk by about four times. The presence of a psychiatric disorder is among the most consistently reported risk factors for suicidal behavior. Specifically, major depressive disorder conveys one of the highest risks for suicidal ideation [21]. Pregnancy is considered a period in which the woman is especially vulnerable to the negative consequences of depression symptoms, which are exacerbated by hormonal changes often experienced during this period ${ }^{[34]}$.

There were many studies agreed with our findings $[7,8,24,26,29]$

A previous study reported that antenatal depression increases current suicide risk by 5.60 times ${ }^{[26]}$. Another research in Brazil showed that depressed pregnant women were 3.83 times more likely to present with suicidality ${ }^{[29]}$. However, a previous study disapproved with ours showed that more than half of the women that experienced SIB were not depressed. The inconsistency was attributed to; they used Mini-International Neuropsychiatric Interview (MINI Plus) to asses major depressive disorder while we used Zagazig depression scale (ZDS) ${ }^{[33]}$.

Regarding anxiety, our study reported that current suicide risk was more among women with anxiety $(\mathrm{N}=13,35.1 \%)$ than those without anxiety and the relation between anxiety and suicidal risk was statistically significant. We found that the presences of anxiety significantly increased the likelihood

\section{Zagazig University Medical Journals}

of suicidal risk by about three times. Pregnancy is a particularly sensitive period for women, being frequently both physically and mentally distressing. Pregnancy is a particularly sensitive period for women, being frequently both physically and mentally distressing. Pregnancy and the birth experience can put women into situations outside their comfort zones, which can induce anxiety; anxiety will be focused on the baby's health, fear of the birthing experience or concern about weight gain, body shape and being a good parent. Hence the anxiety might become severer leading to suicidal behaviors [35]

Many studies agreed with our findings [14, 24, ${ }^{26,}{ }^{29]}$; as has been noted previously, anxiety disorders increased current suicide risk by 3.40 times [26], another research found pregnant women with a generalized anxiety disorder were more likely to have current suicide risk ${ }^{[24]}$.

Also, another study found a higher result for pregnant women suffering from anxiety, pregnant women with symptoms of anxiety had 10.05 times the prevalence of suicidality than those without anxiety symptoms ${ }^{[29]}$.

A study disagrees with ours found that more than half of the women that experienced SIB was not diagnosed with any anxiety disorder. The inconsistency was attributed to they used Mini-International Neuropsychiatric Interview (MINI Plus) to asses anxiety disorder while we used Hamilton anxiety rating scale ${ }^{[33]}$.

\section{Limitations}

This is a cross-sectional observational study that does not entail a follow-up strategy for suicidal patients. More extensive research would preferably target a community sample; this would need a large team of researchers, which was beyond the scope of a master thesis. The study's sample was composed mainly of low-income women who received prenatal care at a public health center at Obstetrics and Gynecology Outpatient clinic at Zagazig university hospitals, which somewhat limits the external validity of the results.

\section{CONCLUSIONS}

By the end of our study, we came up with the following findings; Egyptian pregnant women 


\section{Mohamed et al...}

were under the risk of depression and anxiety which make them more prone to suicide. Pregnant women who exposed to intimate partner aggressiveness were more inclined to suicide. Antepartum suicidal ideation is a common complication of pregnancy that requires increased attention given its association with many adverse maternal, fetal, and infant outcomes. Governmental attention should be paid towards pregnant women, and suicide assessment and prevention programs should be carried out and activated to lower the suicide risk among high-risk groups.

Conflict of Interest: Non declared.

Funding: No funding sources.

\section{REFERENCES}

1- Nock M.K., Joiner T.E., Gordon K.H., Lloyd-Richardson E. \& Prinstein M.J. Nonsuicidal self-injury among adolescents: Diagnostic correlates and relation to suicide attempts. Psychiatry Research. 2006; 144(1): 65-72.

2- World Health Organization Preventing Suicide: A Global Imperative. 2014; 92.

3- Bener A., Gerber L.M. \& Sheikh J. Prevalence of psychiatric disorders and associated risk factors in women during their postpartum period: A major public health problem and global comparison. International Journal of Women's Health. 2012; 4(1): 191200.

4- Ishida K., Stupp P., Serbanescu F. \& Tullo E. Perinatal risk for common mental disorders and suicidal ideation among women in Paraguay.International Journal of Gynecology and Obstetrics. 2010; 110(3): 235-240.

5- Nasreen H.E., Kabir Z.N., Forsell Y. \& Edhborg M. Prevalence and associated factors of depressive and anxiety symptoms during pregnancy: a population based study in rural Bangladesh. BMC Womens Health. 2011; 11:22.

6- Lindahl V., Pearson J. L. \& Colpe L. Prevalence of suicidality during pregnancy and the postpartum. Archives of Women's Mental Health.2005; $8(2)$ : 77-87. 7- Pinheiro R.T, da Cunha Coelho F.M., Da Silva R.A., de Ávila Quevedo L., de Mattos Souza L.D., Castelli R.D., et al. Suicidal behavior in pregnant teenagers in Southern Brazil: social, obstetric and psychiatric correlates. J Affect Disord.2012; 136(3):520-

\section{Zagazig University Medical Journals}

25.

8- Asad N., Karmaliani R., Sullaiman N., Bann C.M., McClure E.M., Pasha O., et al. Prevalence of suicidal thoughts and attempts among pregnant Pakistani women. Acta Obstetricia et Gynecologica Scandinavica.2010; 89(12): 1545-1551. 9- Bayatpour M., Wells R.D. \& Holford S. Physical and sexual abuse as predictors of substance use and suicide among pregnant teenagers. The Journal of Adolescent Health.1992; 13: 128-132. 10- Freitas G.V. \& Botega N.J. Prevalence of depression, anxiety and suicide ideation in pregnant adolescents. Revista Da Associacao Medica Brasileira.2002; 48(3): 245-249. 11- Gausia K., Fisher C., Ali M., \& Oosthuizen J. Antenatal depression and suicidal ideation among rural Bangladeshi women: A community-based study. Archives of Women's Mental Health.2009; 12(5): 351358.

12- Gavin A.R., Tabb K.M., Melville J.L., Guo, Y., \& Katon W. Prevalence and correlates of suicidal ideation during pregnancy. Archives of Women's Mental Health.2011; 14(3): 239-246. 13- Mota N.P., Burnett M. \& Sareen J. Associations between abortion, mental disorders, and suicidal behaviour in a nationally representative sample. Canadian Journal of Psychiatry.2010; 55(4): 239-247. 14- Newport D.J., Levey L.C., Pennell P.B., Ragan K., \& Stowe Z.N. Suicidal ideation in pregnancy: Assessment and clinical implications. Archives of Women's Mental Health.2007; 10(5): 181-187. 15- Beck A. T., Kovacs M., \& Weissman A. Assessment of suicidal intention: The Scale for Suicide Ideation. Journal of Consulting and Clinical Psychology.1979; 47(2): 343-352.

16- Cochrane-Brink K.A., Lofchy J.S., \& Sakinofsky I. Clinical rating scales in suicide risk assessment. General Hospital Psychiatry.2000; 22: 445-451. 17- Dozois D. J., \& Covin R. The Beck Depression Inventory-II (BDI-II), Beck Hopelessness Scale (BHS), and Beck Scale for Suicide Ideation (BSS). 2004. 18- Fawzi M., El-Maghraby Z., El-Amin H., \& Sahloul M. The Zagazig Depression Scale Manual. Cairo: El-Nahda El-Massriya (Arabic). 1982. 19- Hamilton M. Hamilton Anxiety Rating Scale (HAM-A). Journal of Medicine (Cincinnati).1959; 61(4): 81-82. 


\section{Mohamed et al...}

20- Oates M. Perinatal psychiatric disorders: a leading cause of maternal morbidity and mortality. Br Med Bull.2003; 67: 219-229. 21- Nock M.K., Borges G., Bromet E.J., Cha C.B., Kessler R.C. \& Lee S. Suicide and suicidal behavior. Epidemiologic reviews.2008; 30(1): 133-154. 22- Christian L.M. Physiological reactivity to psychological stress in human pregnancy: current knowledge and future directions. Prog Neurobiol.2012: 99 9: 106-16. 23- Gagliardi M., Battistini A., Genovese U. \& Betsos I.M. Suicide in pregnancy. Ital J Crimonology.2014; 4:527-545. 24- Farias D.R., Pinto Tde J., Teofilo M.M., Vilela A.A.F., dos Santos Vaz J., Nardi A. E., et al. Prevalence of psychiatric disorders in the first trimester of pregnancy and factors associated with current suicide risk. Psychiatry Res. 2013; 210(3): 962-968. 25- Vaz J.S., Kac G., Nardi A.E. \& Hibbeln, J.R. Omega-6 fatty acids and greater likelihood of suicide risk and major depression in early pregnancy. Journal of Affective Disorders. 2014; 152-154(1): 76-82. 26- Castro e Couto T., Brancaglion M.Y., Cardoso M.N., Faria G.C., Garcia F.D., Nicolato R. et al. Suicidality among pregnant women in Brazil: prevalence and risk factors. Arch Womens Ment Health.2016; 19: 343-8.

27- Eggleston A.M., Calhoun P.S., Svikis D.S., Tuten M., Chisolm M.S. \& Jones H.E. Suicidality, aggression, and other treatment considerations among pregnant, substancedependent women with posttraumatic stress disorder. Comprehensive Psychiatry.2009; 50(5): $\quad$ 415-423. 28- Huang H., Faisal-Cury A., Chan Y.F., Tabb K., Katon W., \& Menezes P.R. Suicidal ideation during pregnancy: prevalence and associated factors among low-income

\section{Zagazig University Medical Journals}

women in São Paulo, Brazil. Archives of Women's Mental Health.2012; 15(2): 135138.

29- Da Silva R.A., Da Costa Ores L., Jansen K., da Silva Moraes I.G., de Mattos Souza L.D., Magalhães P. et al. Suicidality and associated factors in pregnant women in Brazil. Community Mental Health Journal.2012; 48(3): 392-395. 30- Supraja T.A., Thennarasu K., Satyanarayana V.A., Seena T.K., Desai G., Jangam K. V., et al. Suicidality in early pregnancy among antepartum mothers in urban India. Arch Womens Ment Health.2016; 19: 1101-08.

31- Da Cunha Coelho F.M., Pinheiro R. T., Silva R.A., de Avila Quevedo L., de Mattos Souza L.D., de Matos M.B., et al. Parental bonding and suicidality in pregnant teenagers: A population-based study in southern Brazil. Social Psychiatry and Psychiatric Epidemiology.2014; 49(8): 1241-1248.

32-Alhusen J.L., Frohman N., \& Purcell G. Intimate partner violence and suicidal ideation in pregnant women. Archives of Women's Mental Health.2015; 18(4): 573-578.

33-Onah M.N., Field S., Bantjes J., \& Honikman S. Perinatal suicidal ideation and behaviour: psychiatry and adversity. Archives of Women's Mental Health.2017; 20(2): 321331.

34-Benute G.R.G., Nomura R.M.Y., Jorge V.M.F., Nonnenmacher D., Fráguas Junior R., Lucia, M.C.S.D., et al. Risk of suicide in high risk pregnancy: an exploratory study. Revista Da Associacao Medica Brasileira.2011; 57(5): 583-587.

35-Guardino C.M., \& Dunkel Schetter C. Coping during pregnancy: a systematic review and recommendations. Health psychology review.2014; $\quad 8(1)$ : $\quad 70-94$.

How to cite this article: Mohamed AM , Usama MY , NagyFS ,Reham HM.Prevalence and Associated Factors of Suicide Among Pregnant Women at Zagazig University Hospitals.ZUMJ 2019; 25 (2); 217-226. DOI: $10.21608 /$ ZUMJ.2019.26922 